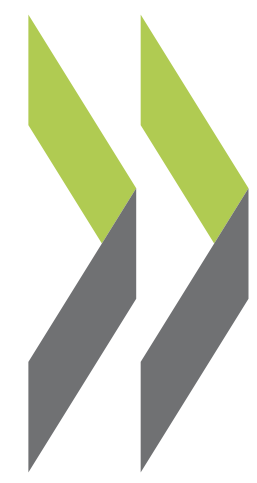

PEB Exchange, Programme on Educational Building 2003/09

\title{
Evaluating School Facilities \\ in Portugal
}

\section{OECD}

https://dx.doi.org/10.1787/673204350523 


\section{EVALUATING SCHOOL FACILITIES IN PORTUGAL}

Portugal has created a questionnaire on educational facilities as part of a larger auditing programme by the General Inspection for Education to evaluate the country's schools.

The main objective of the facilities evaluation is to determine how site, design and management contribute to the performance of curricular activities in each school. And the results of the evaluation process, called the Quality of Educational Facilities and School Network Adaptation Project, will be used to improve the quality of facilities. Many of today's buildings were erected during decades of mass construction to accommodate a growing school population; as new construction is no longer necessary, the country is now focusing on bettering its facilities.

Portugal's Directorate for Quality Educational Facilities (DSQEE) collaborated with the General Inspection in preparing the project guide book along with a questionnaire to determine the image that users have of their school buildings. The project aims to reveal the attitudes of students, teachers, staff and parents toward their school building, their perception of the school's urban integration and the quality of both internal and external spaces.

The questions address the facilities' functionality, comfort, environmental conditions and safety. They range from true/false to multiple choice, to open-ended questions. Examples include "Where do you like to meet your friends?" and "What would you change about your school building?"

In addition to preparing the questionnaire, it was necessary to decide the best way to disseminate it, how many and which users would participate, and who would analyse the responses to ensure coherent statistics. These decisions had to be taken according to the General Inspection for Education's country-wide organisation as well as in collaboration with the Inspection's personnel who would implement the general school evaluation. It was decided to submit the questionnaire to a limited sample of users in each school and to complement it with interviews of teachers and school staff responsible for facilities management. A central department was designated to group and analyse the results.
The DSQEE drafted the questionnaire in collaboration with sociologists specialised in education but uncovered little documentation about similar projects. However they found useful the experience described in "An Evaluation Methodology and Its Application to the Gordon Hall of Science, Cranbrook, Michigan" by Neville Clouten, Jerry Lawrence and Sara Terian, presented at the $9^{\text {th }}$ UIA International Seminar in Portugal in 1990.

\section{For further information, contact:}

José Freire da Silva, Architect

Direcção Geral da Administração Educativa (DSQEE)

Ministry of Education

Portugal

Fax: 351213970310

E-mail:JMSILVA@dgae.min-edu.pt

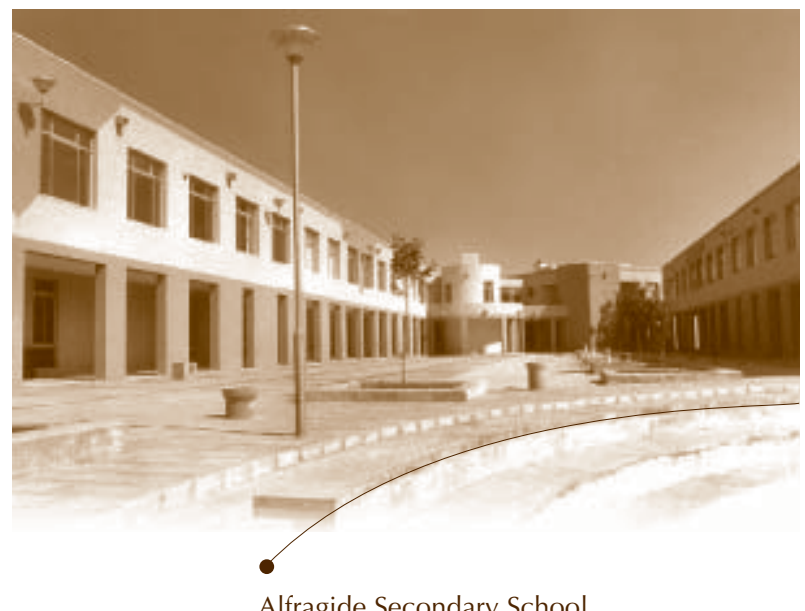
architect: João Mateus

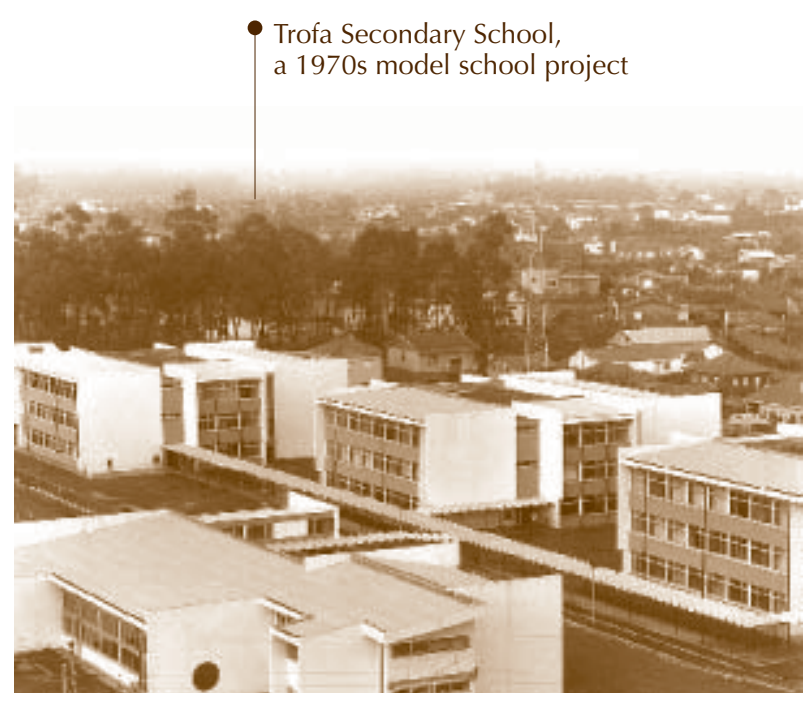

